\title{
ANGIOTENSIN-CONVERTING ENZYME (ACE) GENETIC VARIATION AND LONGEVITY IN PERUVIAN OLDER PEOPLE: A CROSS-SECTIONAL STUDY
}

Teodoro J. Oscanoa ${ }^{1,2,3}$, Edwin C. Cieza ${ }^{1,2,3}$, Frank A. Lizaraso-Soto ${ }^{1}$, María L. Guevara ${ }^{4}$, Ricardo M. Fujita ${ }^{4}$, Román Romero-Ortuño,

1. Corresponding author

Universidad de San Martín de Porres, Facultad de Medicina Humana, Instituto de Investigación, Lima, Perú.

Address: Alameda del Corregidor 1531, La Molina 15024,Lima,Perú.

E-mail: tjoscanoae@gmail.com;Telephone: (511) 942820820

2. Hospital Nacional Guillermo Almenara Irigoyen, Servicio de Geriatría. ESSALUD, Lima, Perú.

3. Universidad Nacional Mayor de San Marcos, Facultad de Medicina, Lima, Perú.

4. Universidad de San Martín de Porres, Centro de Investigación de Genética y Biología Molecular. FMH-USMP. Lima, Perú.

5. Discipline of Medical Gerontology, Mercer's Institute for Successful Ageing, St James's Hospital, Dublin, Ireland.

6. Global Brain Health Institute, Trinity College Dublin, Ireland.

Funding:

ESSALUD - "Premio Kaelin, Instituto de Evaluación e Investigación de Tecnologías de la Salud-IETSI” (Code: 04-IETSI-ESSALUD-2016). Lima, Perú.

Román Romero-Ortuno is funded by Science Foundation Ireland under the President of Ireland Future Research Leaders programme (18/FRL/6188)

Conflict of interest: none 


\begin{abstract}
Background:

Studies have suggested that the Angiotensin-Converting Enzyme (ACE) gene insertion(I)/deletion(D) polymorphism may be associated with human longevity, especially in centenarians. However, it is controversial. Besides, there have been no studies in Peruvians
\end{abstract}

Aim:

To describe the age distribution of the ACE polymorphism in a convenience sample of Peruvian older people.

Subjects and methods:

Cross-sectional study in 104 Geriatric Day Hospital patients in Lima, Perú. The ACE polymorphism was determined in all patients. For the age association, the sample was divided into four categories: young $(<65)$, youngest-old (65-74), middle-old (75-84) and oldest-old ( 85 or more). Association analyses were based on the Chi-square statistic.

Results:

The analysis of the distribution of genotype frequencies was consistent with a population in Hardy-Weinberg equilibrium $(\mathrm{p}=0.62)$. The number $(\%)$ of $\mathrm{D} / \mathrm{D}, \mathrm{I} / \mathrm{D}$ and $\mathrm{I} / \mathrm{I}$ genotypes in the young was $2(14.3 \%), 3(21.4 \%)$ and $9(64.3 \%)$, respectively; in youngest-old: 4 $(11.4 \%), 15(42.9 \%)$ and $16(45.7 \%)$; in middle-old: $6(12.2 \%), 20(40.8 \%)$ and 23 (46.9\%); in oldest-old: $0(0.0 \%), 4(66.7 \%)$ and $2(33.3 \%)$. Chi-square analysis showed no significant genotype distribution differences among age groups $(\mathrm{p}=0.647)$.

Conclusion:

We found no significant age differences in the distribution of the ACE polymorphism in our sample. We recommend further studies with greater statistical power.

Key words: Longevity, Aging, ACE gene, Perú, 


\section{Introduction}

Human longevity is one of the most complex phenotypes to study because it is determined by multiple factors including environment, lifestyle and genes. The heritability of human longevity has been estimated at 10 to 15\% (Kaplanis et al., 2018; Ruby et al., 2018). Heritability is a statistical measure to estimate the degree of variation of a phenotypic trait in a population that could be attributed to genetic rather than environmental factors (Lynch and Bourrat, 2017).

Researchers on longevity genetics are currently studying more than 300 candidate genes in the GenAge database (https://genomics.senescence.info/genes/) and more than 500 in the LongevityMap (https://genomics.senescence.info/longevity/), both of which are part of the Human Ageing Genomic Resources (HAGR: https://genomics.senescence.info) (Tacutu et al., 2018). In a recent review and meta-analysis, a genetic polymorphism in the ACE (Angiotensin Converting Enzyme) gene (rs4340) was among those significantly associated with exceptional human longevity (Revelas et al., 2018). The ACE gene is encoded in the long arm of chromosome 17 (17q23), and the presence or absence of a $288 \mathrm{bp}$ element in the ACE gene gives rise to three genotypes: insertion (I/I), insertion/deletion (I/D) and deletion (D/D) (https://www.snpedia.com/index.php/ACE) (Sayed-Tabatabaei et al., 2006).

The role of ACE in the Renin-Angiotensin-Aldosterone (RAAS) system is to convert Angiotensin I to Angiotensin II; Angiotensin II is a potent vasoconstrictor (i.e. increases cardiac afterload), and it also stimulates smooth, cardiac and skeletal muscle growth. Therefore, ACE may play an important role in the pathogenesis of arterial hypertension, coronary artery disease, heart failure and longevity. A meta-analysis suggested that the ACE D-allele and the DD genotype might confer a modest, albeit significant advantage to reach exceptional longevity in humans (Garatachea et al., 2013).

The two above-mentioned meta-analyses (Garatachea et al., 2013; Revelas et al., 2018) did not include studies from South America. In addition, there had been no studies in Peruvians where the frequency of the ACE polymorphism had been measured in different age groups of older people. In view of this, our aim was to describe the age distribution of the ACE polymorphism in a convenience sample of older Peruvians.

\section{Methods}

A cross-sectional study was carried out that included 104 participants of admixed population of Lima, and older than 60 years. The study was conducted at the Almenara Geriatric Day Hospital in Lima, Perú, between January 2016 and December 2018. The method of patient selection was not probabilistic (convenience sample). The research project was approved by the Almenara Hospital Ethics Committee, and all participants provided signed informed consent.

Genetic analysis

After signing the informed consent, blood samples for each participant were collected in EDTA tubes. DNA was extracted from the leukocytes using the standard phenol/chloroform method and amplified by a polymerase chain reaction process. The ACE I/D polymorphism (rs1799752) was detected using the method described elsewhere (Franken et al., 2004). It must be noted that rs4340 (as reported in (Revelas et al., 2018)) 
and rs1799752 (as measured in our sample) are located in the same 288-bp insertion/deletion. In fact, rs1799752 is a 2-bp indel, compassing the 3'nucleotides of the 288-bp indel of rs4340 (Bouwman et al., 2014).

Sample characteristics

The following variables were used for clinical description of the sample: age, sex, level of education, Charlson Comorbidity Index (Charlson et al., 1994), Barthel Index (disability), timed up \& go as test of mobility (Podsiadlo and Richardson, 1991), MiniMental State Examination score (cognition), and body mass index (nutrition).

Statistical analyses

Descriptive statistics presented as percentage (\%), mean with standard deviation (SD) and range, or median with interquartile range, as appropriate. Chi-square analysis was used for evaluation of deviation from Hardy-Weinberg equilibrium. To study the association between genotype and age, the sample was divided into four categories: young $(<65)$, youngest-old (65-74), middle-old (75-84) and oldest-old (85 or more) (Ihle et al., 2016). Additionally, we divided the total sample into two groups $(</=75 \mathrm{y}$ vs. $>75 \mathrm{y})$. Chi-square analysis was used to test the association between ACE genotypes and age groups. The level of statistical significance was set at $p<0.05$. The SPSS statistical package was used for all the analyses.

\section{Results}

46 men and 58 women entered the study, with a mean age of 73.7 years (range between 60 and 90 years). Table 1 summarises the demographic and clinical characteristics of this convenience sample and Table 2 shows the distribution of ACE genotypes $(n=104)$. With the exception of old-old variable or category $(n=6)$, the I/I genotype was prevalent, followed by I/D and D/D. The Chi-square test of association between ACE genotypes and age was not significant $(\mathrm{p}=0.65)$. The frequency of I allele was $68.3 \%(\mathrm{n}=142)$ and of $\mathrm{D}$ $31.4 \%(n=66)$. The analysis of the distribution of genotype frequencies was consistent with a population in Hardy-Weinberg equilibrium $(\mathrm{p}=0.62)$.

Additionally, we divided the total sample into two age groups $(</=74 y$ vs. $>75)$ and analysed with alleles D and I, and no significant difference was found $(\mathrm{p}=0.745)$. Neither we found significant difference between groups in genotypes $D / D(p=0.837), I / D$ $(\mathrm{p}=0.476)$ and $\mathrm{I} / \mathrm{I}(\mathrm{p}=0.574)$.

In a multiple linear regression predicting age (longevity) in $n=104$ (predictors: female sex, years of education, Charlson Comorbidity Index, ACE I/I status, timed get up and go, Mini-Mental State Examination and body mass index), none of the investigated covariates was a significant predictor.

\section{Discussion}

In this convenience sample of Peruvian attendees to a Geriatric Day Hospital, we found no statistically significant association between ACE genotype and age. Therefore, we could not replicate the previous findings that the D-allele may be associated with increased longevity, reported in two meta-analytical studies by Garatachea et al (OR = 1.16; 95\% CI: 1.06-1.27, p <0.001) (Garatachea et al., 2013) and Revelas et al (OR = $1.11 ; 95 \% \mathrm{CI}=1.01-1.22, \mathrm{p}=0.02$ ) (Revelas et al., 2018). In the present study, the frequency in the group of people over 74 years of age, the $\mathrm{D}$ allele compared to I had an Odds ratio of 1.103 (95\% CI: 0.614 to 1.981 ( $\mathrm{p}=0.744)$. It is important to note that the 
two meta-analytical studies were conducted with studies in the Caucasian, Chinese and Korean population, did not include any studies from South America.

Even though we found no association between ACE genotypes and age-related differences, we add value to the literature in that studies of this ACE polymorphism had not been studied in relation with longevity in a Peruvian sample before. In addition, few studies have described the relationship of the ACE polymorphism in groups under 85 years old (Forero et al., 2006; Kolovou et al., 2014). Although studies of the longevity phenotype are mostly focused on nonagenarians and centenarians, studies of genetic characteristics of younger subgroups are important to study ageing trends in the prevalence of the ACE genotypes.

To our knowledge, only two South American studies exist that provide context to our findings. In Colombia (Bogotá, mestizo population), Forero et al. found a significant lower prevalence of the DD genotype in people over 65 compared to under 65 years old (16\% versus 24\%) (Forero et al., 2006). This would be consistent with our results showed in Table 2. In Brazil (Rio Grande do Sul, Gaucho population, descendants of Italian and German Europeans), Da Cruz et al. found a higher prevalence of DD and I/D genotypes in people over 60 years of age (Da Cruz et al., 2003); in this study there was another group of descendants of Japanese living in Brazil, and in them no relationship was found with DD and I/D polymorphism in people over 60 years. The latter findings would agree with those found in the Asian population, in the Han ethnic group in China and Korea (Choi et al., 2003; Yang et al., 2009), although differ with the results in Xinjiang Uygur in China(Wufuer et al., 2004).

There are important limitations to our study, mostly derived from the small number of older people studied (especially those aged 85 or more years, with only 6 subjects) and being a study based on secondary data analysis of a convenience sample. However, the findings can serve as a basis for studies with larger numbers of older people and other countries of South America. On the other hand, our findings on the frequency of distribution of ACE genotypes in Peru are consistent with other studies, which reported frequencies of II, ID and DD from 50 to $53 \%$; 34 to $45 \%$, and 5 to $13 \%$, respectively. (Bigham et al., 2008, Rupert et al., 2003, Zorrilla et al., 2006).

Further studies are required to replicate the findings of the present study in Peru and South American countries, where the role of the D allele does not seem to influence longevity, on the contrary, it could be applied to the Allele I in conjunction with other environmental and socioeconomic factors.

Declaration of interest: The authors report no conflicts of interest. The authors alone are responsible for the content and writing of the paper. 
Table1. Demographic and clinical characteristics of the sample studied $(n=104)$.

\begin{tabular}{|l|c|}
\hline Variables & All sample \\
\hline Mean age in years(SD) & $73.7(7.4)$ \\
\hline Number of young (<65 years) (\%) & $14(13.5)$ \\
\hline Number of young-old (65-74 years) (\%) & $35(33.7)$ \\
\hline Number of mid-old (75-84 years) (\%) & $49(47.1)$ \\
\hline Number of old-old (85 or more years) (\%) & $6(5.8)$ \\
\hline Number of women (\%) & $58(55.8)$ \\
\hline Number of men (\%) & $46(44.2)$ \\
\hline Mean number of education years (SD) & $11.7(3.8)$ \\
\hline Mean Charlson Comorbidity Index score (SD) & $0.7(1.0)$ \\
\hline Mean Barthel Index (SD) & $97.9(4.7)$ \\
\hline Mean Up \& Go test (seconds) (SD) & $12(4.2)$ \\
\hline $\begin{array}{l}\text { Mean Mini-Mental State Examination (MMSE) score } \\
(\text { SD) }\end{array}$ & $29.0(6.2)$ \\
\hline Mean Body Mass Index(SD) & $27.7(4.0)$ \\
\hline
\end{tabular}

SD: Standard deviation 
Table 2. Distribution of the ACE polymorphism in the sample studied $(n=104)$.

\begin{tabular}{|c|c|c|c|c|c|}
\hline $\begin{array}{c}\text { ACE } \\
\text { genotype }\end{array}$ & $\begin{array}{c}\text { Total } \\
\text { sample(n=10 } \\
4)\end{array}$ & $\begin{array}{c}\text { Young } \\
(\mathrm{n}=14)\end{array}$ & $\begin{array}{c}\text { Young-old } \\
(\mathrm{n}=35)\end{array}$ & $\begin{array}{c}\text { Middle-old } \\
(\mathrm{n}=49)\end{array}$ & $\begin{array}{c}\text { Old-old } \\
(\mathrm{n}=6)\end{array}$ \\
\hline $\mathrm{D} / \mathrm{D}$ & $12(11.5 \%)$ & $2(14.3 \%)$ & $4(11.4 \%)$ & $6(12.2 \%)$ & $0(0.0 \%)$ \\
\hline $\mathrm{I} / \mathrm{D}$ & $42(40.4 \%)$ & $3(21.4 \%)$ & $15(42.9 \%)$ & $20(40.8 \%)$ & $4(66.7 \%)$ \\
\hline $\mathrm{I} / \mathrm{I}$ & $50(48.1 \%)$ & $9(64.3 \%)$ & $16(45.7 \%)$ & $23(46.9 \%)$ & $2(33.3 \%)$ \\
\hline
\end{tabular}

ACE: Angiotensin-Converting Enzyme; D: deletion; I: insertion. 


\section{References}

Bigham A.W, Kiyamu M, León-Velarde F, Parra EJ, Rivera-Ch M, Shriver MD, Brutsaert TD et al. 2008. Angiotensin-converting enzyme genotype and arterial oxygen saturation at high altitude in Peruvian Quechua. High Alt Med Biol. 9, 167-78.

Bouwman, F.G., Boer, J.M.A., Imholz, S., Wang, P., Verschuren, W.M.M., Dollé, M.E.T., Mariman, E.C.M., 2014. Gender-specific genetic associations of polymorphisms in ACE, AKR1C2, FTO and MMP2 with weight gain over a 10year period. Genes \& Nutrition 9, 434.

Charlson, M., Szatrowski, T.P., Peterson, J., Gold, J., 1994. Validation of a combined comorbidity index. J Clin Epidemiol 47, 1245-1251.

Choi, Y.H., Kim, J.H., Kim, D.K., Kim, J.W., Kim, D.K., Lee, M.S., Kim, C.H., Park, S.C., 2003. Distributions of ACE and APOE polymorphisms and their relations with dementia status in Korean centenarians. J Gerontol A Biol Sci Med Sci 58, 227-231.

Da Cruz, I.B., Oliveira, G., Taufer, M., Leal, N.F., Schwanke, C.H., Glock, L., Moriguchi, Y., Moriguchi, E.H., 2003. Angiotensin I-converting enzyme gene polymorphism in two ethnic groups living in Brazil's southern region: association with age. J Gerontol A Biol Sci Med Sci 58, M851-856.

Forero, D.A., Pinzon, J., Arboleda, G.H., Yunis, J.J., Alvarez, C., Catano, N., Arboleda, H., 2006. Analysis of common polymorphisms in angiotensin-converting enzyme and apolipoprotein e genes and human longevity in Colombia. Arch Med Res 37, 890-894.

Franken, R.A., Bellesso, M., Cavazin, A.M., Polônio, I.B., Mattheucci, E., Varga, J., 2004. Associação do polimorfismo do gene da enzima conversora da angiotensina com dados ecocardiográficos em jovens normotensos filhos de hipertensos. Revista da Associação Médica Brasileira 50, 62-67.

Garatachea, N., Marin, P.J., Lucia, A., 2013. The ACE DD genotype and D-allele are associated with exceptional longevity: a meta-analysis. Ageing Res Rev 12, 10791087.

Ihle, A., Jopp, D.S., Oris, M., Fagot, D., Kliegel, M., 2016. Investigating Discontinuity of Age Relations in Cognitive Functioning, General Health Status, Activity Participation, and Life Satisfaction between Young-Old and Old-Old Age. Int J Environ Res Public Health 13.

Kaplanis, J., Gordon, A., Shor, T., Weissbrod, O., Geiger, D., Wahl, M., Gershovits, M., Markus, B., Sheikh, M., Gymrek, M., Bhatia, G., MacArthur, D.G., Price, A.L., Erlich, Y., 2018. Quantitative analysis of population-scale family trees with millions of relatives. Science 360, 171-175.

Kolovou, G., Kolovou, V., Vasiliadis, I., Giannakopoulou, V., Mihas, C., Bilianou, H., Kollia, A., Papadopoulou, E., Marvaki, A., Goumas, G., Kalogeropoulos, P., Limperi, S., Katsiki, N., Mavrogeni, S., 2014. The frequency of 4 common gene polymorphisms in nonagenarians, centenarians, and average life span individuals. Angiology 65, 210-215.

Lynch, K.E., Bourrat, P., 2017. Interpreting Heritability Causally. Philosophy of Science 84, 14-34.

Podsiadlo, D., Richardson, S., 1991. The timed "Up \& Go": a test of basic functional mobility for frail elderly persons. J Am Geriatr Soc 39, 142-148.

Revelas, M., Thalamuthu, A., Oldmeadow, C., Evans, T.J., Armstrong, N.J., Kwok, J.B., Brodaty, H., Schofield, P.R., Scott, R.J., Sachdev, P.S., Attia, J.R., Mather, K.A., 
2018. Review and meta-analysis of genetic polymorphisms associated with exceptional human longevity. Mech Ageing Dev 175, 24-34.

Ruby, J.G., Wright, K.M., Rand, K.A., Kermany, A., Noto, K., Curtis, D., Varner, N., Garrigan, D., Slinkov, D., Dorfman, I., Granka, J.M., Byrnes, J., Myres, N., Ball, C., 2018. Estimates of the Heritability of Human Longevity Are Substantially Inflated due to Assortative Mating. Genetics 210, 1109-1124.

Rupert J.L, Kidd K.K, Norman L.E, Monsalve MV, Hochachka P.W, Devine DV. 2003. Genetic polymorphisms in the Renin-Angiotensin system in high-altitude and lowaltitude Native American populations. Ann Hum Genet. 67, 17-25

Sayed-Tabatabaei, F.A., Oostra, B.A., Isaacs, A., van Duijn, C.M., Witteman, J.C., 2006. ACE polymorphisms. Circ Res 98, 1123-1133.

Tacutu, R., Thornton, D., Johnson, E., Budovsky, A., Barardo, D., Craig, T., Diana, E., Lehmann, G., Toren, D., Wang, J., Fraifeld, V.E., de Magalhaes, J.P., 2018. Human Ageing Genomic Resources: new and updated databases. Nucleic Acids Res 46, D1083-D1090.

Wufuer, M., Fang, M.W., Cheng, Z.H., Qiu, C.C., 2004. [Polymorphism of angiotensin converting enzyme gene and natural longevity in the Xinjiang Uygur people: an association study]. Zhonghua Yi Xue Za Zhi 84, 1603-1606.

Yang, J.K., Gong, Y.Y., Xie, L., Lian, S.G., Yang, J., Xu, L.Y., Gao, S.J., Zhang, Y.P., 2009. Lack of genetic association between the angiotensin-converting enzyme gene insertion/deletion polymorphism and longevity in a Han Chinese population. J Renin Angiotensin Aldosterone Syst 10, 115-118.

Zorrilla P, Mimbacas A, Gascue C, Javiel G, et al. 2006. Prevalencia del polimorfismo I/D del gen de la enzima convertidota de angiotensina (ECA) en la población de Montevideo. Rev. Med. 22, 17-21. 